\title{
MARY WOLLSTONECRAFT: UN CASO DE FEMINISMO ILUSTRADO
}

Rosa Cobo Bedia

Mary Wollstonecraft nace en 1759 en Inglaterra en el seno de una familia que carece de recursos económicos y con un padre alcohólico y de carácter inestable que hizo cambiar continuamente de domicilio a la familia. Estos hechos dificultaron enormemente la formación escolar de Mary. Sin embargo, estas dificultades iniciales pronto se vieron compensadas por su permanente y obsesivo deseo de aprender. Estudió autodidactamente y trabajó desde muy joven, cumpliendo así con el deseo de emanciparse económicamente. La opción de su juventud no fue el matrimonio, como era habitual en aquella época, sino el trabajo. Dama de compañía, institutriz, profesora de escuela, colaboradora de una revista de ideas radicales, The Analitical Review, y escritora fueron las ocupaciones que llenaron la corta vida de Mary Wollstonecraft. En 1787 publica Reflexiones sobre la educación de las niñas, donde combate a favor de una pedagogía no discriminatoria con éstas. En la Analitical Review escribe un artículo titulado "Cartas sobre la educación», en el que defiende las tesis de Catherine Macaulay. En este artículo denuncia nuevamente la discriminación a la que se ven sometidas las niñas en la escuela. Esta crítica se centra en dos aspectos: primero, en una orientación moral consistente en dirigir a las futuras mujeres hacia el matrimonio; $\mathrm{y}$, segundo, en la poca estima y aprecio que dedica la pedagogía a sus facultades intelectuales. En todos estos escritos sobre educación se encuentra el germen de las 
ideas que después desarrollará en Vindicación de los derechos de la mujer. Cuando en 1789 estalla la Revolución en Francia, Mary y todo el círculo de los radicales apoya este suceso con la convicción de que pondría fin a la opresión. Burke, sin embargo, de opinión contraria, publica en 1790 sus Reflexiones sobre la Revolución Francesa, donde muestra el horror que le ha producido la violencia que ha traído la Revolución. Wollstonecraft le contesta de forma inmediata con un panfleto llamado Defensa de los derechos del hombre. Este escrito contiene una reivindicación de los derechos del individuo y de la libertad civil y religiosa, al tiempo que defiende la igualdad y condena la discriminación de que eran objeto las mujeres. A este respecto, es importante señalar que las reivindicaciones morales o políticas de Wollstonecraft transcurren inseparablemente unidas a un discurso de emancipación de las mujeres.

Animada por Thomas Payne redacta, en seis semanas, en el año 1792, Vindicación de los derechos de la mujer. Es indudable que Vindicación puede ser acusado de un estilo literario poco cuidado y de un tono entre apologético y panfletario, pero debe ser defendido por muchas y variadas razones: la defensa de la unidad de la especie y, como consecuencia, de la igualdad entre los géneros, la lucha radical contra los prejuicios, la exigencia de una educación igual para niños y niñas, la reclamación del derecho de ciudadanía para la mujer... El tono apasionado y la convicción con que está escrito no deja impasible a ningún lector ni, sobre todo, lectora. Este es uno de los textos fundacionales del feminismo a partir del cual será imposible contemplar feminismo e Ilustración como dos discursos separados. Vindicación de los derechos de la mujer debe ser estudiado como uno de los orígenes teóricos y morales de lo que en la actualidad se denomina feminismo de la igualdad.

En 1797 Mary Wollstonecraft muere en Londres a la edad de treinta y ocho años. Antes pasó una estancia en Francia y escribió un Análisis histórico y moral de la Revolución Francesa ${ }^{1}$. Si habitualmente se habla de la estrecha relación entre la vida y la obra de cualquier autor, en el caso de Wollstonecraft ambas están unidas por voluntad propia. En este mismo sentido escribía Brailsford cuando decía que la vitalidad de sus ideas nacían de sus propias experiencias personales ${ }^{2}$.

Tras esta breve presentación de la figura de Mary Wollstonecraft hemos seleccionado el capítulo $\mathrm{V}$ de Vindicación de los derechos de la mujer. En este capítulo, nuestra autora toma como referente polémico a Rousseau, concretamente un capítulo del Emilio que tiene por objeto la educación de Sofía.

Los datos de carácter histórico pueden encontrarse más detalladamente en el prólogo que Charo Ema ha escrito para la presente edición. Mary Wollstonecraft, Vindicación de los derechos de la mujer, Tribuna Feminista, Ed. Debate, Madrid, 1977.

2 Brailsford, Sbelley, Godwin y su circulo, p. 149, México, 1986. Traducción española. Primera edición en inglés 1913, Ed. FCE. 
En este capítulo, el filósofo ginebrino describe pormenorizada y minuciosamente el paradigma de mujer natural que encarna precisamente en Sofía, la compañera de Emilio. La primera observación de Wollstonecraft consiste en explicar que Sofía es un modelo de mujer que habita en la imaginación de Rousseau pero que carece de realidad histórica. Sofía no es como las mujeres ni las mujeres son como Sofía. La artificialidad de Sofía es una de las reiteradas críticas de nuestra autora.

La crítica de Wollstonecraft a Rousseau es hecha desde dentro del propio pensamiento rousseauniano, utilizando las mismas nociones e incluso los mismos paradigmas que utiliza Rousseau, pero dándoles la vuelta, mostrando sus contradicciones internas, oponiendo continuamente al deber ser de Rousseau un es concreto y real. Mary Wollstonecraft, conocedora de la Ilustración y ferviente partidaria de las Luces, toma nociones de Rousseau, a las que da un contenido diferente e incluso contrario. Estado de naturaleza, virtud, máscara, educación... son conceptos utilizados por la autora inglesa en un sentido radicalmente ilustrado.

Para entender en toda su extensión Vindicación y para comprender la crítica a J. J. Rousseau es necesario explicar el concepto de razón en Wollstonecraft. La noción de razón de nuestra autora tiene su génesis en el bon sens cartesiano pero al que se le añade una nueva virtualidad. Siguiendo a Celia Amorós, podemos decir que en Wollstonecraft, al igual que en Poullain de la Barre, el bon sens se extiende al espacio social para operar como desenmascaramiento de prejuicios, tradiciones, costumbres y valores morales o sociales. Esta razón radicalmente ilustrada es la que, a mi juicio, vertebra Vindicación. No es extraño, por tanto, comprobar el combate de la autora inglesa contra cualquier tipo de prejuicio, sobre todo aquellos que legitiman prerrogativas injustas o despotismos inmorales. En esta dirección, Mary Wolistonecraft usa la razón como instrumento crítico contra los prejuicios que impiden la emancipación de las mujeres. Desde este contexto teórico-moral es desde el que realiza la crítica a las concepciones educativas de Rousseau. A juicio de Wollstonecraft, el principal error de Rousseau radica en que analiza las costumbres y los hábitos de las mujeres como si fuesen rasgos innatos. Rousseau, en opinión de nuestra autora, no se da cuenta o no quiere darse cuenta, que desde que nacemos nuestros gustos están socialmente dirigidos y que esta socialización conduce a las niñas a asumir valores y pautas de sometimiento a los varones. En definitiva, la educación de las niñas consiste en hacerlas dependientes, y cuando esto se ha conseguido se decreta que la dependencia es natural.

Su reivindicación de una educación igual para niños y niñas la apoya en su concepto de estado de naturaleza. Su concepción de la naturaleza es ilustrada en el sentido de que es normativa. El individuo, en su origen, no es una tabula rasa, como pretendía Locke, sino que es portador de unos derechos naturales que tienen su génesis en la razón. En este sentido, es iusnatu- 
ralista, sirviéndole dicho iusnaturalismo para afirmar la unidad de la especie, es decir, la unidad de los géneros. Si ambos géneros tienen los mismos derechos naturales, ambos deberán tener los mismos derechos sociales. Este razonamiento conduce finalmente al feminismo de la igualdad. La gran crítica de la autora inglesa a Rousseau consiste en poner de manifiesto que la mujer natural rousseauniana es, en realidad, la mujer social. La operación de Rousseau, a juicio de Wollstonecraft, es la siguiente: primero establece los deberes de cada sexo y, después, sobre dichos deberes construye las inclinaciones naturales. Por tanto, su concepto de estado de naturaleza tiene su origen en la propia historia. Desde esta reflexión se pueden observar dos estados de naturaleza diferentes, según se fundamenten en los derechos de los varones o en los de las mujeres. En opinión de Wollstonecraft, el sometimiento a causa de costumbres y hábitos impuestos por la sociedad ha construido una segunda naturaleza en las mujeres que Rousseau confunde con el estado de naturaleza.

El concepto de virtud rousseauniano también es atacado por Mary Wollstonecraft. La virtud en Rousseau se encuentra ligada a la recuperación de lo natural, y la recuperación de la naturaleza se plasma en la Voluntad General. Debido a esto, el hombre virtuoso es el buen ciudadano. Sin embargo, la mujer no puede acceder a la virtud porque no participa en la Voluntad General ni, en consecuencia, es ciudadana. La virtud, en cuanto expresión del sujeto responsable del proceso social, no se extiende a las mujeres. Por esto, Rousseau habla de una virtud específica para las mujeres. Esta virtud se traduce en la fidelidad al esposo, en la educación de los hijos como futuros ciudadanos, en el cuidado de la familia y la casa... Wollstonecraft nuevamente, apoyándose en la unidad del género humano, cree en una virtud única para todos los individuos. Si la razón es universal, la virtud, que es su expresión moral, también será universal. Como dice Celia Amorós, Mary Wollstonecraft entiende la virtud al modo kantiano como autonomía de la razón. La virtud de la autora inglesa no está fundada en intereses particulares o en utilidades sociales, sino en la propia razón. La virtud, así considerada, será la forma de expresarse social y moralmente la razón.

Wollstonecraft tampoco acaba de comprender el elogio a la ignorancia de las mujeres que realiza Rousseau. Si la mujer es la responsable de transmitir la noción de virtud a los futuros ciudadanos, a los futuros sujetos del contrato social, ¿cómo puede hacerlo si ella misma no posee esa clase de virtud? Más aún, ¿si es incluso incapaz de reflexionar?

En este aspecto como en otros, Wollstonecraft ataca con precisión las contradicciones del pensamiento de Rousseau en lo que concierne a las mujeres. Si la igualdad es el rasgo fundamental del estado de naturaleza, ¿por qué la mujer debe estar sometida al varón? Si el modelo político esbozado en el Contrato Social pretende establecer la igualdad del estado natural, ¿por qué las mujeres deben ser excluidas de la Voluntad General, que es el 
instrumento que constituye a los individuos en libres e iguales? Pero si contrariando la noción de estado de naturaleza rousseauniana se decide que las mujeres, naturalmente, son más débiles e inferiores que los varones, ¿por qué no establecer mecanismos de carácter social o político para compensar su supuesta inferioridad natural?

Vindicación es mucho más que una lúcida crítica a Rousseau y a cuantos filósofos han escrito sobre el sometimiento de las mujeres a los varones. La crítica de esta autora va dirigida al conjunto de los varones por su apropiación histórica de la razón. Más aún, su obra desborda la crítica teórica y moral para entrar en el espacio de la acción social: su reivindicación del derecho de ciudadanía y de la participación de las mujeres en los gobiernos como instrumentos necesarios de su emancipación dan buena prueba de ello. 